\title{
Desempenho da argamassa técnica decorativa antes e após envelhecimento acelerado em câmara de intemperismo
}

\author{
Performance of monolayer surface coating \\ before and after aging in a weathering chamber
}

Adriano de Paula Silva ${ }^{1}$, Antônio Neves de Carvalho Júnior ${ }^{1}$, Gabriel Henriques Rabelo Gouvêa ${ }^{2}$, Mauro Eugênio Lechi Vieira ${ }^{1}$

\footnotetext{
${ }^{1}$ Departamento de Engenharia de Materiais e Construção, DEMC/UFMG, Avenida Presidente Antônio Carlos, n. 6627 , bloco I, $3^{\circ}$ andar, sala 3408, CEP 31.270-901, Belo Horizonte, Minas Gerais, Brasil.

${ }^{2}$ Faculdade de Engenharia e Arquitetura, FEA/FUMEC, Rua Cobre, n. 200, CEP 30310-190, Belo Horizonte, Minas Gerais, Brasil.

E-mail: apsilva.eng@gmail.com, ancj@ufmg.br, maurolec@hotmail.com, gabrielhrg.ep@gmail.com.
}

\section{RESUMO}

O sistema monocamada se apresenta como uma alternativa ao sistema de revestimentos convencionais em argamassa e pintura decorativa. Neste trabalho foi realizada a análise do desempenho do sistema monocamada em relação a resistência de aderência à tração e estanqueidade pelo método do cachimbo antes e após a submissão de placas de substrato padrão ao envelhecimento acelerado em câmara de intemperismo. Protótipos foram submetidos a ciclos de envelhecimento, equivalentes à 6 anos e 3 meses de exposição natural. Conclui-se que os substratos não intemperizados são mais permeáveis que os intemperizados. A resistência de aderência à tração dos substratos com e sem intemperismo, atenderam aos parâmetros estabelecidos pela norma ABNT NBR 16648 [1].

Palavras-chave: revestimento, argamassa, monocamada, desempenho, durabilidade.

\begin{abstract}
The monolayer system presents itself as an alternative to the conventional mortar and decorative painting system. In this work, the performance analysis of the mono-layer system was carried out in relation to the tensile bond strength and tightness by the pipe method before and after the submission of standard substrate plates to accelerated aging in a weathering chamber. Prototypes were subjected to aging cycles, equivalent to 6 years and 3 months of natural exposure. It is concluded that the non-weathered substrates are more permeable than the weathered ones. The tensile bond strength of substrates with and without weathering met the parameters established by ABNT NBR 16648 [1].
\end{abstract}

Keywords: coating, mortar, monolayer, performance, durability.

\section{INTRODUÇÃO}

As estruturas devem ser duráveis de modo a desempenhar as funções para as quais foram dimensionadas, sob as condições de agressividade local e do entorno aos quais estão inseridas ao longo da vida útil projetada país [2,3]. A durabilidade dos planos verticais também é responsabilidade das fachadas dos edifícios [2]. As fachadas devem impedir a entrada de substancias degradantes.

Ataque de sulfatos, reação álcali-agregado, lixiviação, carbonatação e ataque de cloretos são alguns dos processos químicos degradantes das estruturas. Para o desencadeamento desses processos agressivos são necessários não só os agentes deletérios específicos de cada processo, mas também da presença de água [4, $5]$. 
A água além de funcionar como mecanismo de transporte dos agentes deletérios à estrutura [6], também é uma substância necessária para o desenvolvimento dos processos que agridem as mesmas.

Grande parte dos edifícios construídos no Brasil utilizam o revestimento de argamassa, sejam eles residenciais, comerciais e industriais. Essa técnica tradicional é uma prática que reporta ao início da colonização do país [7, 8].

Embora largamente utilizado, o revestimento em argamassa tradicional sofre com altos índices de desperdícios, falhas durante os processos e problemas que ocorrem durante a vida útil da edificação, culminando em custos elevados de manutenção [2, 8].

$O$ revestimento tradicional multicamadas exige das construtoras maior controle e planejamento dos processos e das etapas, além da cura adequada das camadas, o que infelizmente não é comum nas obras.

Nesse contexto, o revestimento monocamada surgiu como uma opção de racionalização do processo construtivo. A ABNT NBR 16648 [1] nomeou o revestimento monocamada como argamassa técnica decorativa (ATD).

A ATD é uma argamassa mineral industrial fornecida no estado anidro, ensacada e pronta para uso, sendo necessário adicionar apenas água para sua aplicação em quantidade definida por cada fabricante. $\mathrm{O}$ tempo de utilização também é variável, dependendo do fabricante e das condições de temperatura e umidade relativa do ar durante a aplicação [9, 10]. Esta argamassa é constituída de cimento branco, cal hidratada, agregados (calcário dolomítico) e aditivos. Dentre os aditivos pode-se citar os hidrofugantes, espessantes, pigmentos, retentores de água e incorporadores de ar [9].

A argamassa técnica decorativa tem como função regularizar o substrato, e, por ser pigmentada, também servir de acabamento final, auxiliando na proteção da estrutura contra agentes agressivos e intempéries e no desempenho acústico e térmico da edificação.

Neste trabalho é proposta a análise do desempenho da ATD acerca dos parâmetros resistência de aderência à tração e estanqueidade pelo método do cachimbo, antes e após a submissão de placas de substrato padrão ao envelhecimento acelerado em câmara de intemperismo. O envelhecimento acelerado, assim como os ensaios de estanqueidade e de resistência de aderência à tração não foram realizados segundos os parâmetros da ABNT NBR 16648 [1], devido a publicação da mesma ter ocorrido após o início dos ensaios. Entretanto, para os ensaios de resistência à tração foi possível utilizar os parâmetros desta norma.

\section{MATERIAIS E MÉTODOS}

Para avaliar o desempenho da argamassa técnica decorativa foram realizados ensaios de estanqueidade pelo método do cachimbo - CSTC NIT.224 [11] e de resistência de aderência à tração de acordo com a ABNT NBR 15258 [12] e exposição do revestimento a ciclos de intemperismos.

\subsection{Aplicação da ATD no substrato padrão}

A argamassa técnica decorativa foi aplicada diretamente no substrato padrão de tamanho $(25 \times 50 \times 2) \mathrm{cm}$ produzido pela ABCP - Associação Brasileira de Cimento Portland e fabricado conforme a ABNT NBR $14081[13]$.

Utilizou-se neste trabalho ATDs de cores, lotes e datas de fabricação diferentes, tendo em vista que a ATD não é vendida no mercado varejista ou atacadista em geral. Segundo o fabricante, a constituição das ATDs utilizadas são as mesmas, apenas as cores são diferentes.

Foram ensaiadas vinte placas de substrato padrão aplicadas com ATD, sendo executadas em dois lotes com intervalo de tempo de aproximadamente 1 ano entre os mesmos. De cada conjunto de dez substratos, metade (cinco) foi submetida à câmara de intemperismo e as outras cinco placas não foram envelhecidas. As datas dos ensaios estão nos gráficos de barras (figuras 6 a 11) apresentados.

As especificações das ATDs utilizadas foram relacionadas na Tabela 1. 
Tabela 1: Especificações das ATDs*.

\begin{tabular}{c|c|c}
\hline & Lote 1 & Lote 2 \\
\hline Cor & Marfim (nº 3150) & Platina $\left(\mathrm{n}^{\mathbf{o}} 3102\right)$ \\
\hline Data da fabricação & $18 / 05 / 2017$ & $01 / 06 / 2018$ \\
\hline Validade & 180 dias após a data de fabricação & 180 dias após a data de fabricação \\
\hline Peso do saco & $30 \mathrm{~kg}$ & $30 \mathrm{~kg}$ \\
\hline Água & 5,4 litros / saco (18\% do peso da ATD) & 5,4 litros / saco (18\% do peso da ATD) \\
\hline
\end{tabular}

* informações fornecidas pelos fabricantes.

As placas de substrato padrão foram limpas com escova de cerdas plásticas, para a retirada de material pulverulento e a ATD foi misturada de acordo com as recomendações presentes na embalagem do produto.

A figura 1 apresenta as ferramentas utilizadas (a), as placas de substrato padrão (b), o gabarito articulado que delimita a espessura adotada (c) e o substrato já com a ATD aplicada (d).

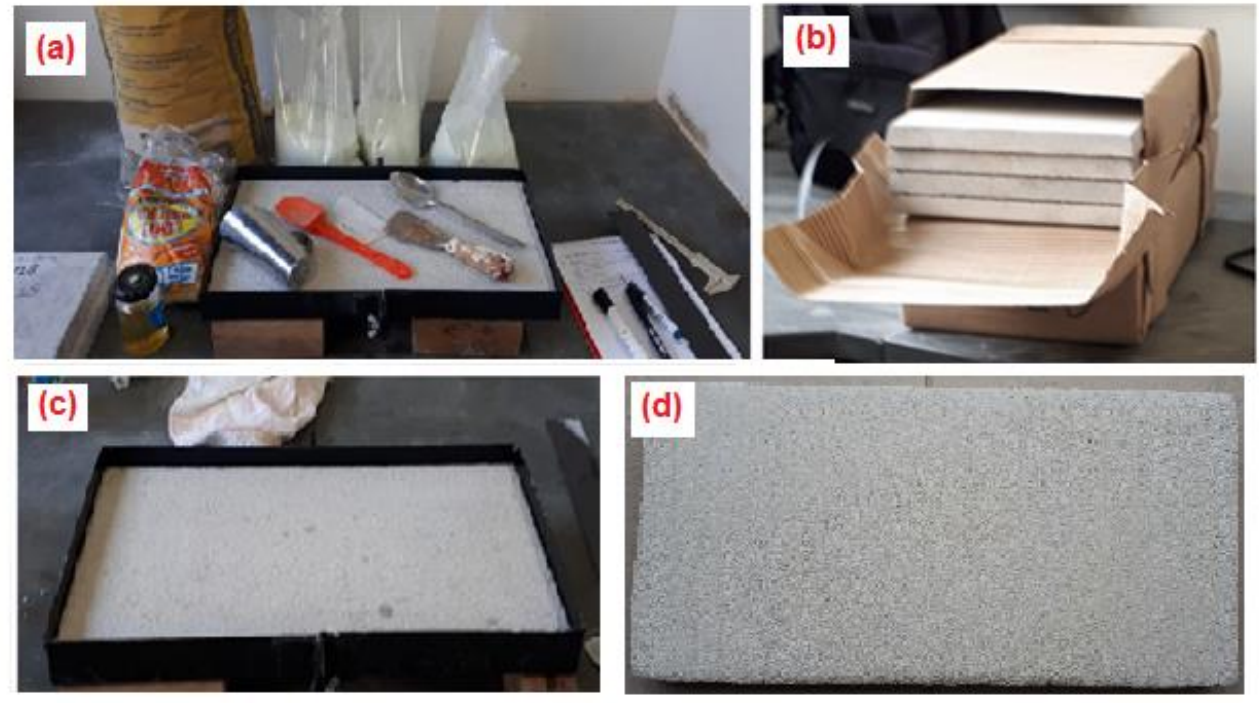

Figura 1: Ferramentas utilizadas (a), os substratos padrões (b), o gabarito articulado (c) e o substrato já com a ATD aplicada (d).

Adotou-se a espessura de dois centímetros de acordo com a ABNT NBR 15258 [12]. Os substratos executados ficaram três dias em ambiente de laboratório, protegidos de danos mecânicos, sob a temperatura ambiente na faixa de $23^{\circ} \mathrm{C}$ e umidade relativa do ar na faixa de $63 \%$.

No quarto dia os substratos foram dispostos em posição vertical, em temperatura ambiente de laboratório, com proteção entre os mesmos para que não ocorresse nenhum dano à superfície até a cura de 28 dias.

\subsection{Ensaio de resistência de aderência à tração}

A ABNT NBR 15258 [12] especifica o método de ensaio de resistência de aderência à tração (RA) da argamassa técnica decorativa aplicada sob substrato padrão executado em laboratório. A Figura 2 (a) apresenta o plano de ensaio adotado e a Figura 2 (b) apresenta o substrato padrão já ensaiado quanto à RA e em ensaio quanto ao método do cachimbo. 


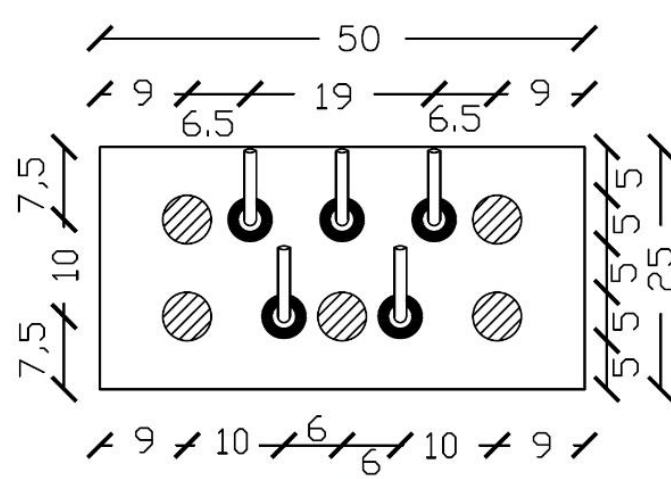

(a)

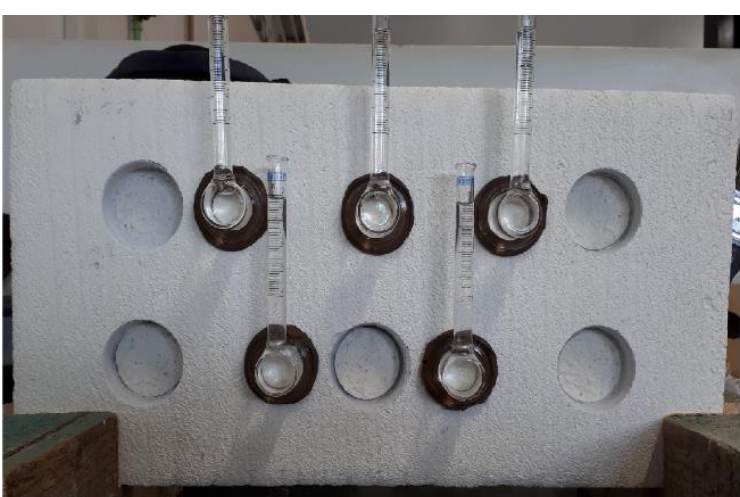

(b)

* Legendo:

- Enscio de resistência à aderência à tração

d

- Ensaio de cstonqueidodo

Figura 2: Plano de ensaios adotado (medidas em centímetros).

Optou-se por ensaiar cinco corpos de prova para a determinação da resistência de aderência à tração em cada placa, a fim de que sobrasse espaço suficiente para a execução dos ensaios de estanqueidade na mesma placa. Utilizou-se o espaçamento de 50 milímetros das bordas para que fosse possível usar o aderímetro de tração apoiado diretamente sobre a placa de substrato padrão, ou seja, sem a necessidade de suporte que poderia atrapalhar os resultados do ensaio de arrancamento.

A intenção de fazer ambos os ensaios na mesma placa é verificar a existência ou não de alguma relação entre os resultados do ensaio de resistência à aderência à tração e os resultados dos ensaios de estanqueidade antes e depois do envelhecimento acelerado.

O ensaio de resistência de aderência consiste na realização de corte com serra copo para delimitação do corpo de prova. Deve-se ter muito cuidado, ao realizar o corte, para não exercer torção na argamassa, podendo contribuir para dispersão dos resultados [14].

Após a cura da cola utilizada para fixação da pastilha metálica acopla-se o equipamento de tração (Proceq, modelo Dyna Z16) à mesma aplicando-se o esforço de tração de maneira lenta, constante e perpendicular ao corpo de prova. Registra-se o esforço de ruptura, recalculando esse esforço com base na área real pré-calculada e também a forma de ruptura junto com o percentual de ocorrência, sendo: ruptura no substrato (S); ruptura na interface substrato/argamassa (S/A); ruptura na argamassa (A) e falha na colagem da peça metálica (F), conforme ABNT NBR 15258 [12].

Segundo a diretriz SINAT [9], a resistência de aderência à tração da monocamada externa no estado endurecido deve ser maior ou igual a 0,30 $\mathrm{MPa}$, sendo que esse limite deve ser atendido por oito de cada doze determinações de resistência de aderência à tração realizadas. A ABNT NBR 16648 [1] especifica o critério mínimo de aceitação dos resultados encontrados nos ensaios de laboratório, onde o revestimento ATD monocamada externo deve apresentar tensão de ruptura individual maior ou igual a 0,50 MPa. Quando a ATD é exposta a ciclos de exposição ao calor e choque térmico, a mesma deve apresentar resultado maior ou igual a 0,25 MPa em oito dos 12 corpos de prova ensaiados e a média do resultado dos oito corpos de prova não pode ser menor que $50 \%$ da média dos quatro maiores resultados de tração obtidos antes da ação do calor e choque térmico. Neste estudo estas análises foram realizadas tomando-se o total dos ensaios de arrancamento realizados para cada lote.

\subsection{Ensaio de estanqueidade segundo CSTC NIT.224 [11]}

A absorção e a permeabilidade dos revestimentos à água tornam-se um estudo importante quando são analisadas as manifestações patológicas e a deterioração das construções causadas pela penetração da água. $\mathrm{O}$ Centre Scientifique et Technique de la Construction - CSTC, através do NIT 224 [11], e a Réunion Internationale des Laboratoires d'Essais et de Recherches sur les Matériaux et les Constructions - RILEM, 
através do test II.4 [15], apresenta um método simples e não destrutivo para medir o volume de água absorvida por um material dentro de um período de tempo especificado. Este método é também conhecido como "Método do Cachimbo" $[14,16]$.

Utilizou-se o método do cachimbo que consiste de tubos de vidro graduados de 0 a $4 \mathrm{ml}\left(1 \mathrm{ml}=1 \mathrm{~cm}^{3}\right)$ em forma de "L", conhecidos como tubos de Karsten fixados à superfície a ser ensaiada por meio de selante elastomérico $[14,16]$.

Quando o tubo está preenchido até nível máximo, a pressão da água exercida na superfície do revestimento $\left(5,31 \mathrm{~cm}^{2}\right)$ é equivalente a $98 \mathrm{~mm}$ de altura da água, o que corresponde à pressão exercida por um vento na ordem de $40 \mathrm{~m} / \mathrm{s}(\approx 140 \mathrm{~km} / \mathrm{h})$ perpendicularmente à superfície de medição (Figura 3). Com o intuito de se verificar a absorção em um prazo maior, executou-se a leitura após 1, 5, 10, 15, 20, 25 e 30 minutos de exposição do ATD à pressão da água, utilizando um cronômetro para a marcação dos tempos de cada leitura.

A Figura 3 mostra a área com diâmetro de $(27 \pm 0,5) \mathrm{mm}$, que representa a superfície de contato entre a água e a ATD. Esta área deve estar livre de selante elastomérico para não interferir na absorção de água durante o ensaio.
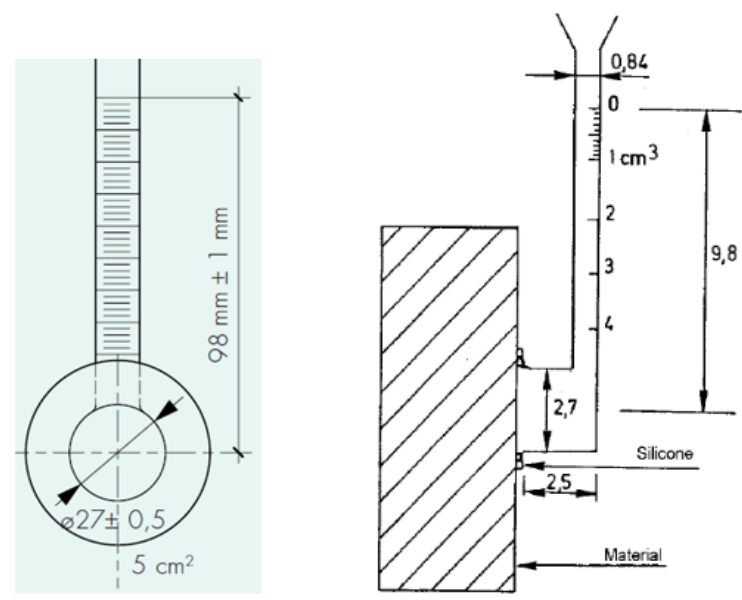

Figura 3: Área com diâmetro de $27( \pm 0,5) \mathrm{mm}$ que representa a superfície de contato entre a água e a ATD [11].

Para minimizar as dificuldades de interpretação e tornar mais objetiva a análise dos resultados foi analisada a eficiência do revestimento de acordo com a CSTC NIT.224 [11], calculando a diferença entre as leituras $\Delta(15-5), \Delta(20-10), \Delta(25-15)$ e $\Delta(30-20)$ antes e após o envelhecimento, conforme a Equação 1.

$$
\text { Eficiência }(\%)=1-\left(\frac{\Delta(15-5) \text { após o envelhecimento } \times 100}{\Delta(15-5) \text { antes do envelhecimento }}\right)
$$

Sobre a eficiência, cabe salientar que ela interpreta a absorção de água ao longo dos pontos amostrais de todo o ensaio, ou seja, analisa as variações de absorção nos tempos de 5, 10, 15, 20, 25 e 30 minutos. Quando a eficiência resulta em um valor positivo, significa que o $\Delta$ (15-5) após o envelhecimento foi menor que o $\Delta$ (15-5) antes do envelhecimento, indicando que a absorção após o envelhecimento é menor que antes do intemperismo. Quando a eficiência resulta em um valor negativo, significa que o $\Delta$ (15-5) após o envelhecimento foi maior que o $\Delta(15-5)$ antes do envelhecimento, indicando que a absorção após o envelhecimento é maior do que antes do intemperismo.

\subsection{Câmara de intemperismo}


O ensaio de envelhecimento acelerado utilizando a câmara de intemperismo consistiu em submeter as ATDs aplicadas nas placas de substrato padrão a ciclos extremos de variação de temperatura e umidade relativa do ar no intuito de acelerar a degradação do revestimento. Utilizou-se a câmara de intemperismo da marca Feltron, modelo Climatic Test Chamber, número 3423/16, série 059, fabricada em 2003.

Para permitir a homogeneidade da temperatura e umidade relativa do ar no interior da câmara de intemperismo, optou-se por colocar apenas 5 placas de substrato padrão no seu interior. A distância entre as grades e a variação posicional das placas permitiram a livre circulação do ar, conforme apresenta a Figura 4.

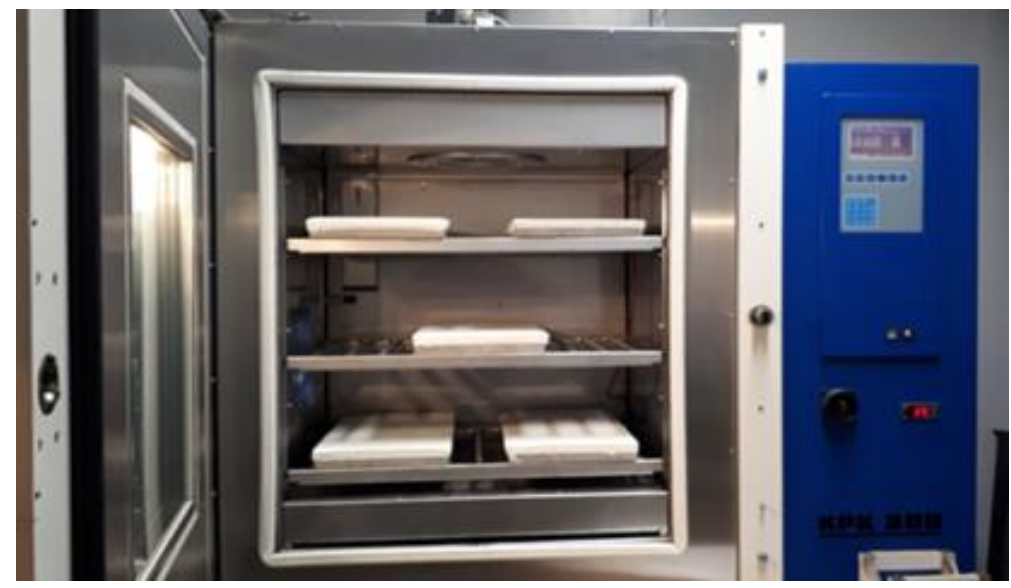

Figura 4: Disposição das placas de substrato padrão dentro da câmara de intemperismo.

No intuito de submeter as ATDs a extremos de temperatura e poder verificar o seu desempenho antes e após o intemperismo, estabeleceu-se neste trabalho as temperaturas de $80^{\circ} \mathrm{C}\left( \pm 4^{\circ} \mathrm{C}\right)$ com $56 \%( \pm 5 \%)$ de umidade relativa do ar por 90 minutos e $5^{\circ} \mathrm{C}\left( \pm 4^{\circ} \mathrm{C}\right)$ com umidade relativa de $80 \%( \pm 5 \%)$ por 90 minutos, sendo necessário 60 minutos para as trocas de temperatura.

A temperatura de $80^{\circ} \mathrm{C}$ foi adotada por ser a temperatura indicada pela ABNT NBR 15575 [3]. A temperatura mínima de $5^{\circ} \mathrm{C}$ foi adotada porque a câmara de intemperismo utilizada varia $\pm 4^{\circ} \mathrm{C}$ durante o seu funcionamento. Então, como o revestimento monocamada não pode ser utilizado em áreas que apresentem temperaturas negativas, segundo SINAT [9], adotou-se essa temperatura como mínima.

A umidade relativa do ar no interior da câmara foi de $56 \%$ e $80 \%$, utilizadas para a temperatura alta e baixa, respectivamente. Estes valores foram adotados por serem a média da umidade relativa do ar nas capitais brasileiras nos dias de maior e menor temperatura durante o ano de 2017, segundo dados obtidos no site do Instituto Nacional de Meteorologia (Inmet).

A Figura 5 representa a variação da temperatura relacionada com o tempo utilizado nos 20 ciclos programados na câmara de intemperismo acelerado deste trabalho. 


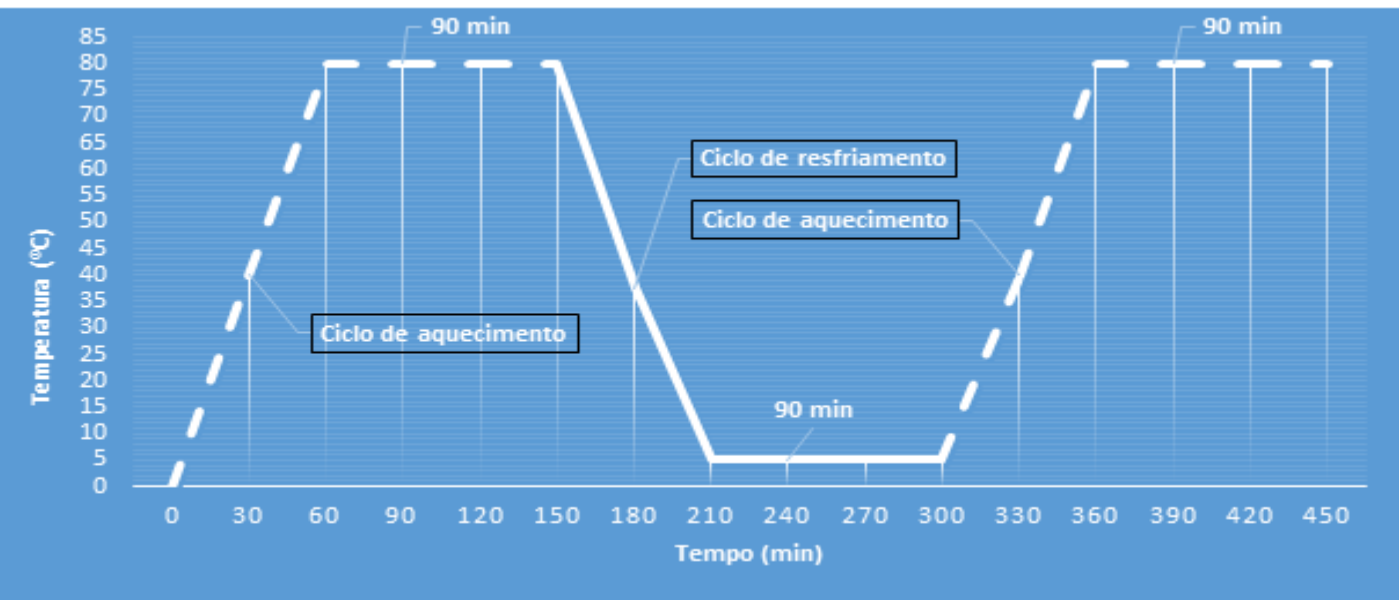

Figura 5: Variação da temperatura e do tempo utilizados nos ciclos programados.

No trabalho desenvolvido por Bitencourt da Silva [17], definiu-se que 20 dias de intemperismo acelerado correspondem a 480 horas, sendo 443 ciclos de 65 minutos cada, que equivalem a aproximadamente 5 anos de fachada. Este ciclo leva em consideração temperatura máxima de $70^{\circ} \mathrm{C}$, temperatura mínima de $30^{\circ} \mathrm{C}$ sendo 5 minutos para resfriamento até $30^{\circ} \mathrm{C}$ e 10 minutos para aquecimento até $70^{\circ} \mathrm{C}$, permanecendo nessa temperatura por 50 minutos, repetindo essa sequência 443 vezes.

A câmara de envelhecimento utilizada neste trabalho precisa de 60 minutos para alternar a temperatura de $80^{\circ} \mathrm{C}$ e $56 \%$ de umidade para $5^{\circ} \mathrm{C}$ e umidade de $80 \%$. Com isso, para intemperizar com o mesmo tempo de Bitencourt e considerando os 60 minutos que nossa máquina necessita, foram executados 600 horas de intemperismo consecutivas em cada conjunto de 5 placas. Fazendo uma regra de três simples entre os 5 anos de fachada conseguidos através de 480 horas de intemperismo de Bitencourt da Silva [17] e as 600 horas de intemperismo executados neste trabalho, verifica-se a correspondência de aproximadamente 6 anos e 3 meses de exposição natural da fachada segundo sistemática de conversão de intemperismo desenvolvido por [17].

\section{ANÁLISE E DISCUSSÃO DOS RESULTADOS}

Neste item são apresentados e discutidos os resultados obtidos dos ensaios de resistência à aderência à tração e de estanqueidade das ATDs aplicados sobre as placas de substrato padrão submetidas ou não ao envelhecimento acelerado.

\subsection{Resultados do ensaio de resistência de aderência à tração}

A Figura 6 apresenta o resultado do ensaio de resistência de aderência à tração dos 10 substratos do lote 1 com ATD produzida conforme diretrizes do SINAT [9]. 


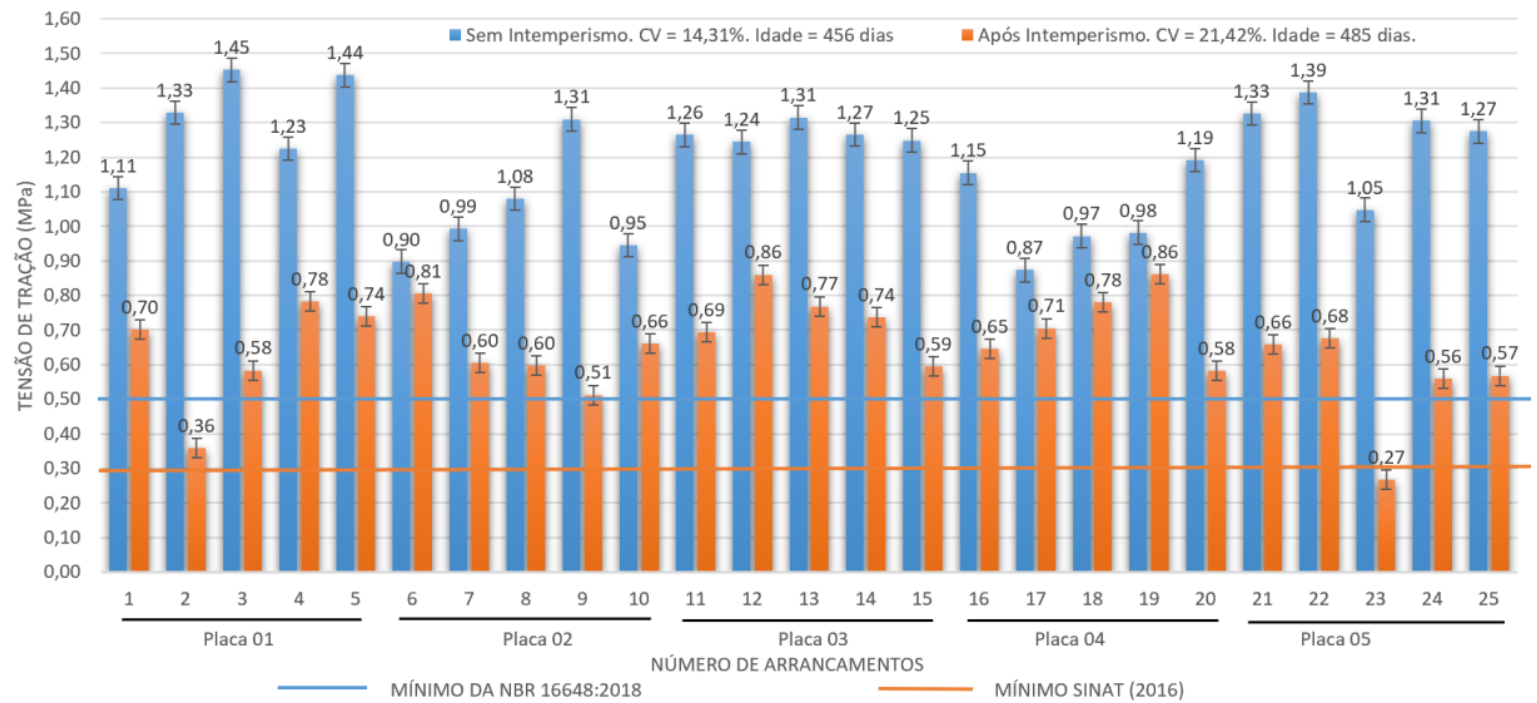

Figura 6: Resultado de resistência de aderência dos 10 substratos do lote 1.

Cinco substratos foram submetidos ao envelhecimento acelerado em câmara de intemperismo durante 600 horas ininterruptas e 5 placas não foram envelhecidas.

Apenas duas pastilhas envelhecidas não obtiveram valores de resistência de aderência superiores a 0,50 MPa, mínimo segundo a ABNT NBR 16648 [1] para a condição de laboratório. O resultado inferior a 0,30 $\mathrm{MPa}$ é pouco representativo por ser o único resultado entre 50 pastilhas arrancadas e o limite de 0,30 MPa foi atendido em mais de oito pastilhas de cada doze arrancamentos realizados.

As placas sem envelhecimento apresentaram RA médio de 1,19 $\mathrm{MPa}$ e as placas submetidas ao envelhecimento obtiveram média de $0,65 \mathrm{MPa}$ (redução de $45 \%$ ).

$\mathrm{O}$ coeficiente de variação $(\mathrm{CV})$ representa a heterogeneidade dos resultados obtidos e, de maneira geral, é um indicador de qualidade.

$\mathrm{O} \mathrm{CV}$ das amostras sem intemperismo $(\mathrm{CV}=14,31 \%)$ foi inferior ao coeficiente de variação das amostras envelhecidas $(\mathrm{CV}=21,42 \%)$. Essa diferença aliada à redução da RA das amostras envelhecidas confirma a degradação natural causada pela câmara de intemperismo.

Quanto à forma de ruptura, a Tabela 2 apresenta a média das RAs e dos tipos de ruptura das placas sem e com intemperismo.

Tabela 2: Média das resistências de aderência e os tipos de ruptura dos substratos sem e com intemperismo do lote 1.

\begin{tabular}{c|c|c|c|c|c}
\hline \multirow{2}{*}{ Tratamento } & \multirow{2}{*}{$\begin{array}{c}\text { Média } \\
\text { de RA } \\
\text { (MPa) }\end{array}$} & $\begin{array}{c}\text { Ruptura } \\
\text { substrato } \\
(\mathbf{S})\end{array}$ & $\begin{array}{c}\text { Ruptura } \\
\text { substrato/argam } \\
\text { assa (S/A) }\end{array}$ & $\begin{array}{c}\text { Ruptura argamassa } \\
\text { (A) }\end{array}$ & $\begin{array}{c}\text { Ruptura } \\
\text { argamassa/cola } \\
\text { (F) }\end{array}$ \\
\hline $\begin{array}{c}\text { Placas sem } \\
\text { intemperismo }\end{array}$ & 1,19 & $0 \%$ & $51 \%$ & $49 \%$ & $0 \%$ \\
\hline $\begin{array}{c}\text { Placa com } \\
\text { intemperismo }\end{array}$ & 0,65 & $0 \%$ & $53 \%$ & $47 \%$ & $0 \%$ \\
\hline
\end{tabular}

Verifica-se que a ruptura adesiva em ambas condições ficaram muito próxima da ruptura coesiva, indicando que a resistência na argamassa é levemente maior que a resistência na interface substrato/argamassa.

A Figura 7 apresenta o resultado do ensaio de resistência de aderência à tração dos 10 substratos do lote 2 . 


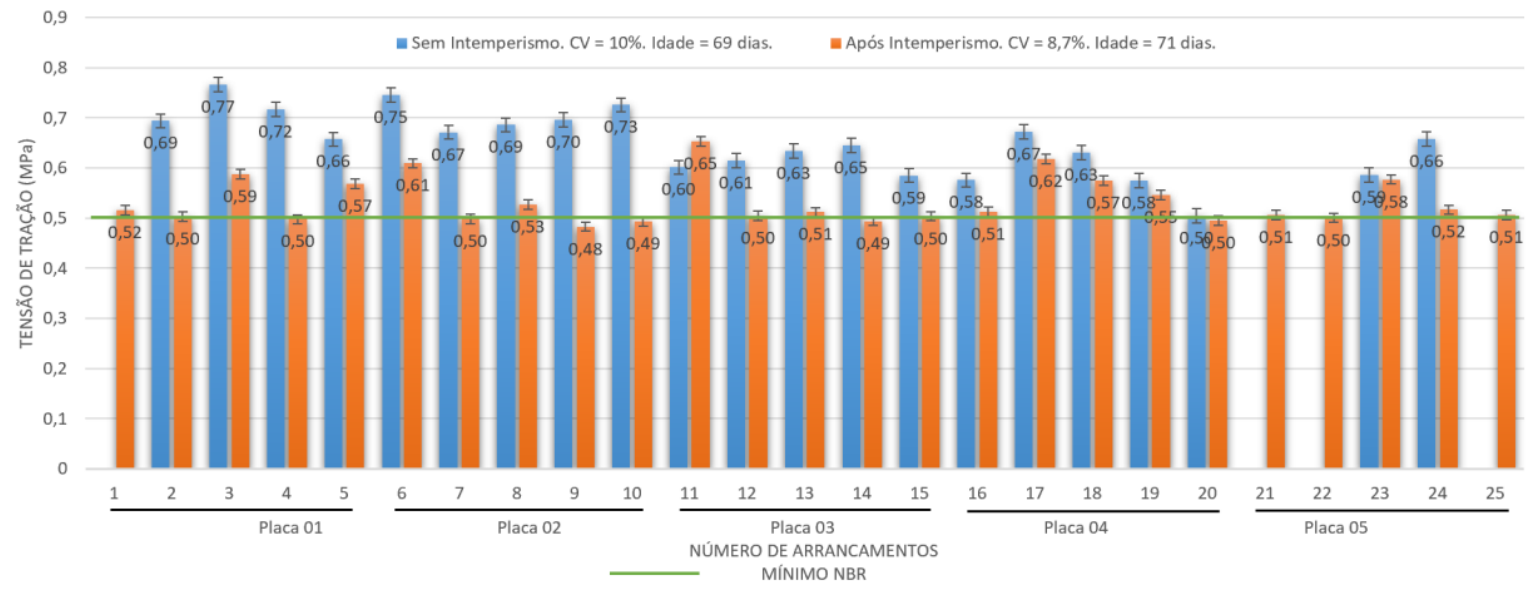

Figura 7: Resultado de resistência de aderência dos 10 substratos do lote 2.

A ATD utilizada no lote 02 foi produzida conforme a ABNT NBR 16648 [1]. Dos 10 substratos executados, 5 foram ensaiados sem intemperismo e 5 foram ensaiados após o intemperismo, sendo 69 e 71 dias as respectivas idades dos revestimentos. Durante a execução dos ensaios, três pastilhas da placa 05 romperam-se antes da execução do ensaio de arranchamento.

Segundo a ABNT NBR 16648 [1], o valor mínimo de RA deve ser maior ou igual a 0,50MPa para ensaios realizados em laboratório e $0,3 \mathrm{MPa}$ para ensaios executados na obra, ambos para ATDs para uso externo. No entanto, ainda segundo a referida NBR, a resistência de aderência à tração após ciclos de exposição ao calor e choque térmico, a ATD deve apresentar resultado maior ou igual a 0,25 MPa em oito dos 12 corpos de prova ensaiados e a média dos resultados dos oito corpos de prova não pode ser menor que $50 \%$ da média dos quatro maiores resultados de tração obtidos antes da ação do calor e choque térmico. Portanto, verifica-se que os 3 resultados de RAs menores que 0,50 MPa são irrelevantes e que $100 \%$ das amostras foram aprovadas pela ABNT NBR 16648 [1]. Portanto, os resultados obtidos são satisfatórios tanto para ensaios realizados em laboratório, quanto para ensaios realizados na obra.

Nota-se menor dispersão de resultados de RA após o envelhecimento, pois o coeficiente de variação (CV) das amostras sem envelhecimento foi de $10 \%$ e o CV das placas envelhecidas foi 8,7\%. A resistência de aderência à tração média e o tipo de ruptura das amostras são apresentadas na Tabela 3.

Tabela 3: Média das resistências de aderência e os tipos de ruptura dos substratos sem e com intemperismo do lote 2.

\begin{tabular}{c|c|c|c|c|c}
\hline \multirow{2}{*}{ Tratamento } & \multirow{4}{*}{$\begin{array}{c}\text { Média de } \\
\text { RA (MPa) }\end{array}$} & $\begin{array}{c}\text { Ruptura } \\
\text { substrato } \\
\text { (S) }\end{array}$ & $\begin{array}{c}\text { Ruptura } \\
\text { substrato/argamassa } \\
\text { (S/A) }\end{array}$ & $\begin{array}{c}\text { Ruptura } \\
\text { argamassa } \\
\text { (A) }\end{array}$ & $\begin{array}{c}\text { Ruptura } \\
\text { argamassa/cola } \\
\text { (F) }\end{array}$ \\
\hline $\begin{array}{c}\text { Placas sem } \\
\text { intemperismo }\end{array}$ & 0,65 & $0 \%$ & $92 \%$ & $3 \%$ & $5 \%$ \\
\hline $\begin{array}{c}\text { Placa com } \\
\text { intemperismo }\end{array}$ & 0,53 & $0 \%$ & $84 \%$ & $16 \%$ & $0 \%$ \\
\hline
\end{tabular}

A média da RA dos substratos sem e com intemperismo foi 0,65 $\mathrm{MPa}$ e 0,53 $\mathrm{MPa}$, respectivamente, indicando redução de 19,5\% na resistência de aderência à tração após o envelhecimento. A Tabela 4 apresenta o quadro resumo com os resultados do ensaio de aderência à tração executados em ambos os lotes. 
Tabela 4: Resumo com os resultados do ensaio de resistência de aderência executados.

\begin{tabular}{|c|c|c|c|c|c|c|}
\hline Lote & Tratamento & $\begin{array}{l}\text { Idade do } \\
\text { substrato }\end{array}$ & $\begin{array}{l}\text { Número RAs } \\
\text { executados }\end{array}$ & $\begin{array}{l}\text { Média das } \\
\text { RAs (MPa) }\end{array}$ & CV & $\begin{array}{c}\text { Ruptura } \\
\text { predominante }\end{array}$ \\
\hline \multirow{2}{*}{ Lote 01} & $\begin{array}{c}\text { Sem } \\
\text { envelhecimento }\end{array}$ & 456 dias & 25 & $1,19 \mathrm{MPa}$ & $14,31 \%$ & Adesiva/Coesiva \\
\hline & $\begin{array}{c}\text { Com } \\
\text { envelhecimento }\end{array}$ & 485 dias & 25 & $0,65 \mathrm{MPa}$ & $21,42 \%$ & Adesiva/Coesiva \\
\hline \multirow{2}{*}{ Lote 02} & $\begin{array}{c}\text { Sem } \\
\text { envelhecimento }\end{array}$ & 69 dias & 22 & $0,65 \mathrm{MPa}$ & $10,00 \%$ & Adesiva \\
\hline & $\begin{array}{c}\text { Com } \\
\text { envelhecimento }\end{array}$ & 71 dias & 25 & $0,53 \mathrm{MPa}$ & $8,70 \%$ & Adesiva \\
\hline
\end{tabular}

Por se tratar de um ensaio comparando a média de RA dos lotes, verifica-se redução de RA de $45 \%$ entre as placas sem envelhecimento e 18,5\% entre as placas envelhecidas. Acredita-se que a diferença de idade justifica esta ocorrência, devido o processo de consolidação das fases hidratadas com o passar do tempo. Verifica-se que a ruptura adesiva predominou em ambas condições, indicando que a resistência na argamassa é maior que a resistência na interface substrato/argamassa.

\subsection{Resultado do ensaio de estanqueidade}

A Figura 8 apresenta o resultado de absorção de água dos 5 substratos do lote 1 com ATD produzido conforme diretrizes da SINAT [9] sem intemperismo.

Verifica-se que a absorção de água para o ATD sem intemperismo aumenta gradativamente ao longo do tempo. Para a maioria das amostras a absorção máxima ao final de 30 minutos ficou entre 0,1 e $0,2 \mathrm{~cm}^{3}$.

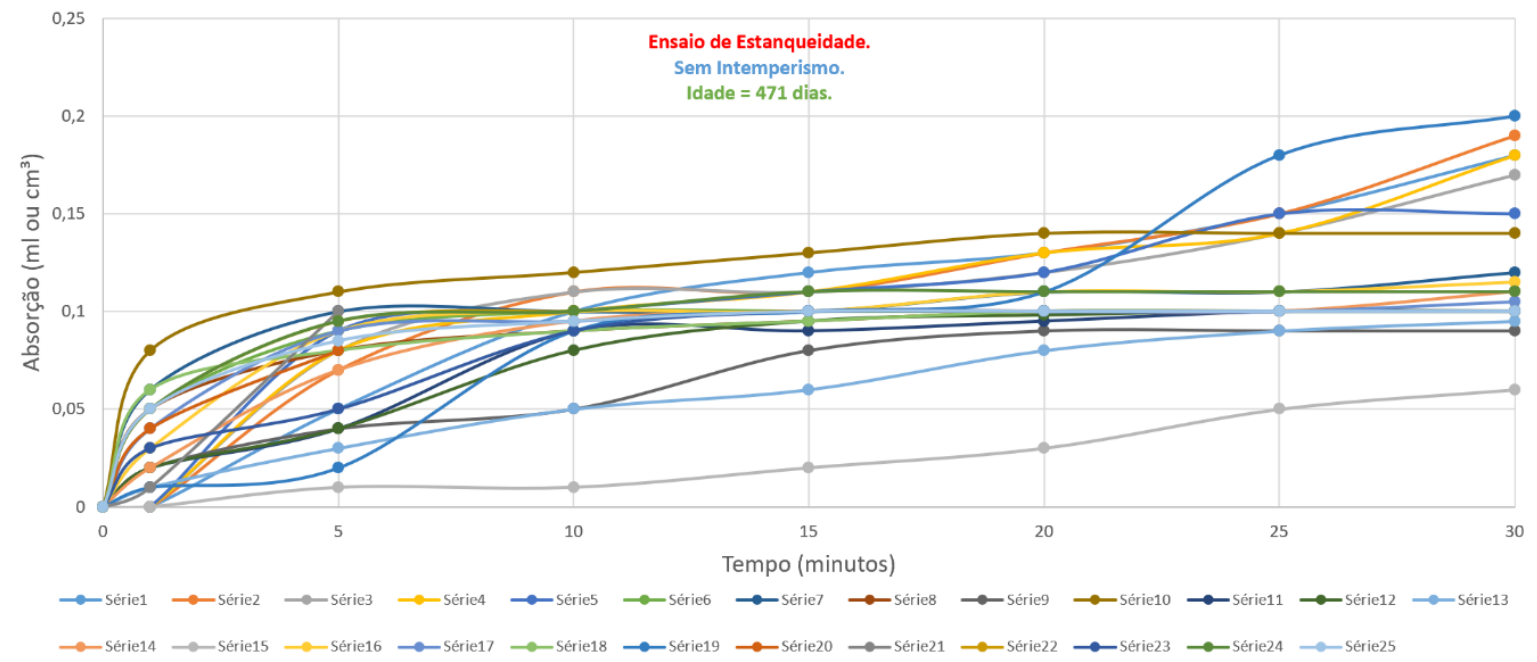

Figura 8: Absorção de água dos 5 substratos do lote 1 sem intemperismo.

A Figura 9 apresenta o resultado de absorção de água dos 5 substratos do lote 1 com ATD produzido conforme diretrizes da SINAT [9] com intemperismo. 


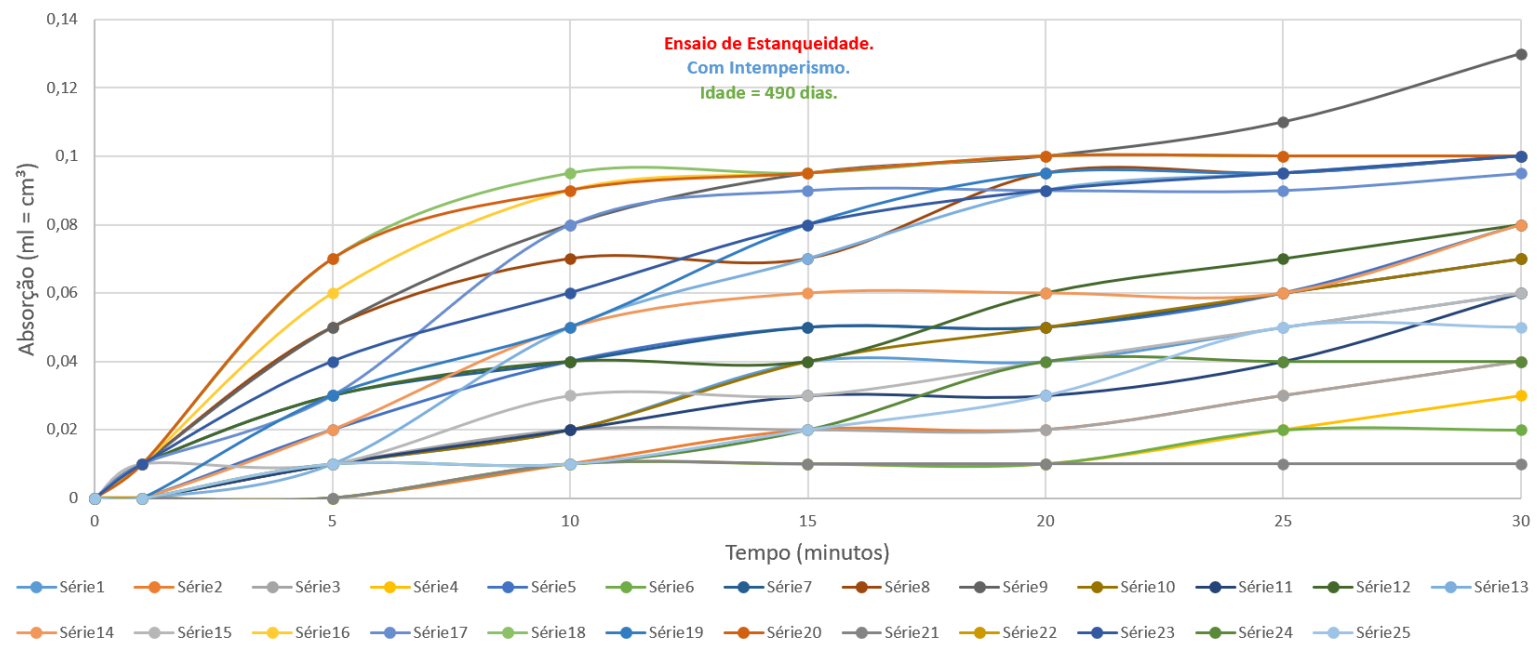

Figura 9: Absorção de água dos 5 substratos do lote 1 com intemperismo.

Após o intemperismo, além da absorção aumentar ao longo do tempo, nota-se grande dispersão de resultados nas amostras. A absorção máxima ao final de 30 minutos é $0,1 \mathrm{~cm}^{3} \mathrm{com}$ um ponto isolado a 0,13 $\mathrm{cm}^{3}$.

Analisando os gráficos percebe-se nas placas submetidas ao intemperismo que a absorção de água foi menor quando comparado à absorção nas placas sem o tratamento. Essa constatação indica menor permeabilidade do revestimento envelhecido. Acredita-se que no envelhecimento possa ter ocorrido mudanças de fases dos compostos hidratados do cimento que interferiram na porosidade e capilaridade do sistema, afetando assim de forma direta a permeabilidade do revestimento.

De acordo com CSTC NIT.224 [11], pode-se calcular a eficiência do revestimento calculando a diferença entre a leitura de 15 e 5 minutos $(\Delta(15-5))$ antes e após o envelhecimento, conforme a Equação 1 informada anteriormente.

As tabelas 5 e 6 apresentam o cálculo da eficiência. Ambos os quadros mostram a evolução da absorção de acordo com o tempo de ensaio. Os quadros amarelos representam o resultado ideal, onde a absorção após mais de 6 anos de envelhecimento foi inferior à absorção das placas sem o envelhecimento acelerado. Já os quadros verdes representam preocupação, pois indicam que a absorção após o intemperismo foi superior à absorção das placas sem envelhecimento. Os quadros azuis indicam que a absorção antes e após o intemperismo foram iguais. Os quadros alaranjados representam a absorção antes do intemperismo iguais a zero, ou seja, a leitura se manteve ao longo dos tempos de leitura. Os quadros brancos indicam que não houve leitura devido a deficiências na montagem do aparato do ensaio ocorrendo vazamento de água no selante utilizado na fixação do tubo de Karsten.

A Tabela 5 apresenta o resultado do cálculo da eficiência levando em consideração os resultados de absorção antes e após o intemperismo dos substratos do lote 01 . 
Tabela 5: Resultado do cálculo da eficiência do lote 1.

\begin{tabular}{|c|c|c|c|}
\hline \multicolumn{4}{|c|}{ Resumo das Eficiências } \\
\hline $\boldsymbol{\Delta} \mathbf{( 1 5 - 5 )}$ & $\boldsymbol{\Delta} \mathbf{( 2 0 - 1 0 )}$ & $\boldsymbol{\Delta} \mathbf{( 2 5 - 1 5 )}$ & $\boldsymbol{\Delta ( \mathbf { 3 0 - 2 0 } )}$ \\
\hline 11 quadros & 6 quadros & 9 quadros & 8 quadros \\
\hline 10 quadros & 11 quadros & 3 quadros & 4 quadros \\
\hline 1 quadro & 2 quadros & 4 quadros & 1 quadro \\
\hline 1 quadro & 1 quadro & 6 quadros & 8 quadros \\
\hline 0 & 2 quadros & 0 & 1 quadros \\
\hline
\end{tabular}

Legenda:

\begin{tabular}{|l|l}
\hline & * Eficiência positiva -Absorção após intemperismo menor que antes do intemperismo. \\
& $*$ Eficiência negativa - Absorção após intemperismo maior que antes do intemperismo. \\
& $*$ Eficiência neutra - Absorção igual antes e após o intemperismo. \\
& $*$ Indica que a absorção antes do intemperismo foi igual a 0. \\
& $*$ Sem leitura de absorção antes ou após o intemperismo.
\end{tabular}

Analisando o quadro resumo verifica-se que os quadros alaranjados aumentaram de quantidade à medida que o tempo do ensaio evoluiu, apresentando uma tendência de estabilização de absorção para as placas antes do intemperismo. A diferença entre os quadros amarelos e verdes ao longo do ensaio, exceto no $\Delta$ (20-10), aumentaram em relação ao $\Delta$ (15-5), aliado ao aumento dos quadros alaranjados, indicam que a absorção após o intemperismo é menor que antes do envelhecimento acelerado em todo o ensaio.

Nota-se que a maior absorção de água aos 15 minutos de ensaio para as placas do lote 01 sem intemperismo foi $0,13 \mathrm{~cm}^{3} \mathrm{e} 0,095 \mathrm{~cm}^{3}$ para as placas envelhecidas.

As Figuras 10 e 11 apresentam os gráficos de absorção de água dos substratos do lote 02 com 70 dias de idade sem intemperismo e dos substratos envelhecidos com idade de 72 dias respectivamente. A Figura 11 apresenta a absorção dos substratos com intemperismo.

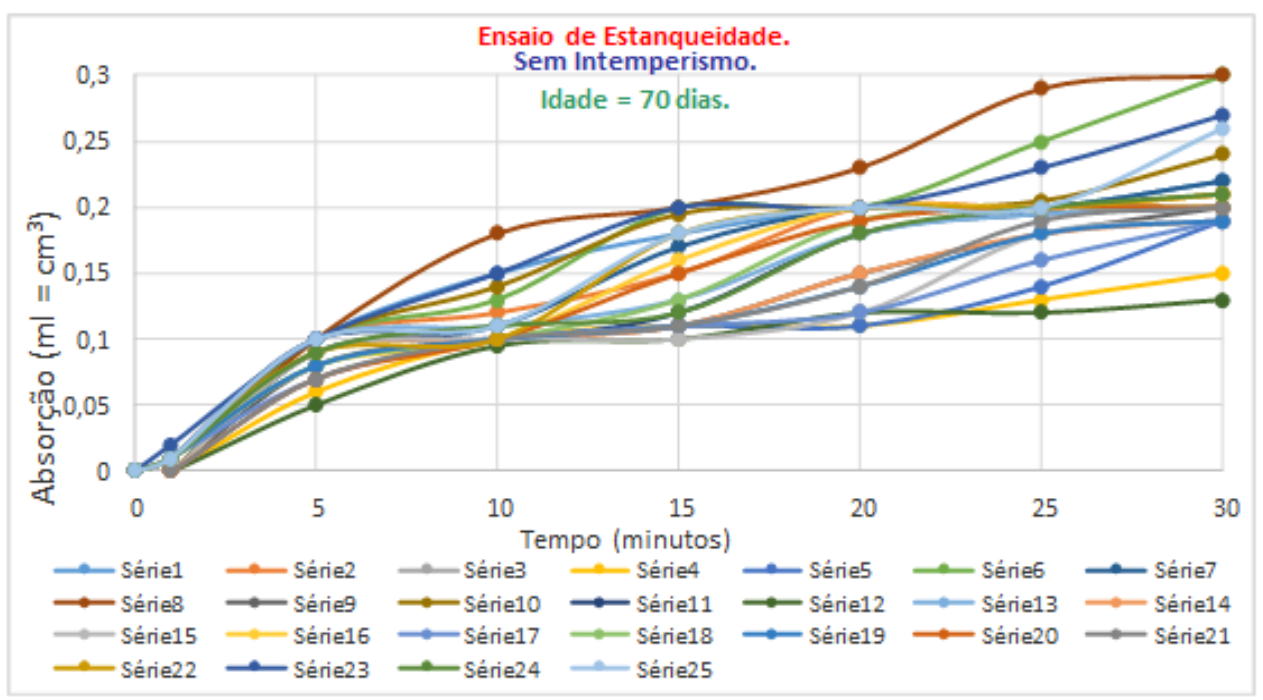

Figura 10: Absorção de água dos 5 substratos do lote 2 sem intemperismo. 


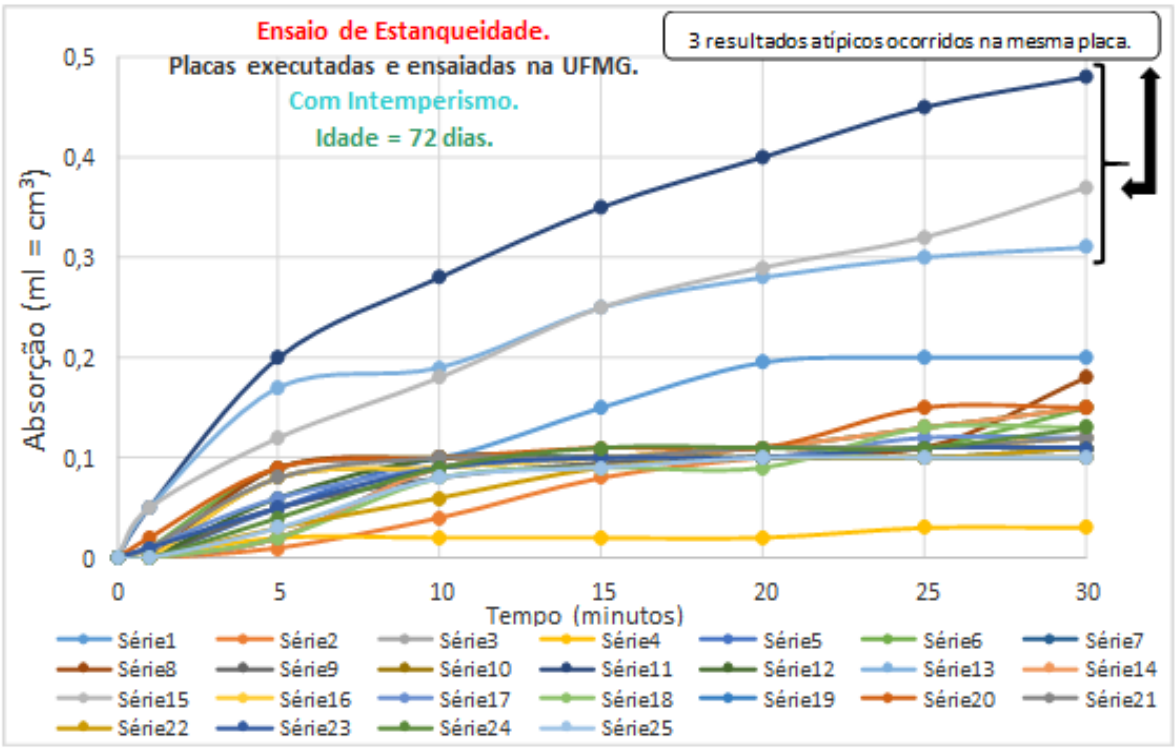

Figura 11: Absorção de água dos 5 substratos do lote 2 com intemperismo.

Nota-se na Figura 11, 3 curvas com valores destoantes das demais curvas. Verificando a planilha de resultados de absorção, percebe-se que eles foram obtidos na linha superior da mesma placa, posição 1,3 e 5 (ver Figura 2). Esses 3 conjuntos de resultados destoam dos demais devido aos valores elevados de absorção. Acredita-se que esses resultados possam ser decorrência de variações no processo de fabricação e aplicação da ATD no substrato padrão. Desconsiderando as 3 curvas destoantes da Figura 11, percebe-se que a absorção após o intemperismo é menor que a absorção das placas não envelhecidas.

Identifica-se a absorção máxima de $0,15 \mathrm{~cm}^{3}$ aos 15 minutos de ensaio das placas com intemperismo e $0,2 \mathrm{~cm}^{3}$ de absorção máxima aos 15 minutos para as placas não envelhecidas. De acordo com o resumo das eficiências, apresentado na tabela 6 , verifica-se o ótimo desempenho em relação a permeabilidade da ATD envelhecida em relação às placas sem intemperismo, devido a grande maioria dos quadros amarelos.

Tabela 6: Resultado do cálculo da eficiência do lote 2 .

\begin{tabular}{|c|c|c|c|}
\hline \multicolumn{4}{|c|}{ Resumo das Eficiências } \\
\hline $\boldsymbol{\Delta} \mathbf{( 1 5 - 5 )}$ & $\boldsymbol{\Delta} \mathbf{( 2 0 - 1 0 )}$ & $\boldsymbol{\Delta} \mathbf{( 2 5 - 1 5 )}$ & $\boldsymbol{\Delta} \mathbf{( 3 0 - 2 0 )}$ \\
\hline 11 quadros & 16 quadros & 17 quadros & 10 quadros \\
\hline 9 quadros & 4 quadros & 3 quadros & 7 quadros \\
\hline 2 quadros & 0 & 0 & 4 quadros \\
\hline 0 & 0 & 1 quadro & 0 \\
\hline 1 quadro & 3 quadros & 3 quadros & 2 quadros \\
\hline
\end{tabular}

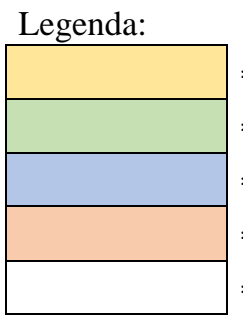

Eficiência positiva -Absorção após intemperismo menor que antes do intemperismo.

* Eficiência negativa - Absorção após intemperismo maior que antes do intemperismo.

* Eficiência neutra - Absorção igual antes e após o intemperismo.

* Indica que a absorção antes do intemperismo foi igual a 0 .

* Sem leitura de absorção antes ou após o intemperismo.

A Tabela 7 apresenta o quadro resumo com os resultados dos ensaios de estanqueidade executados. 
Tabela 7: Resumo com os resultados dos ensaios de estanqueidade executados.

\begin{tabular}{c|c|c|c}
\hline Lote & $\begin{array}{c}\text { Absorção de água dos substratos } \\
\text { sem intemperismo }\end{array}$ & $\begin{array}{c}\text { Absorção de água dos substratos } \\
\text { com intemperismo }\end{array}$ & Eficiência \\
\hline Lote 01 & $\begin{array}{c}0,05 \text { a } 0,2 \mathrm{~cm}^{3} \\
471 \text { dias }\end{array}$ & $\begin{array}{c}0,01 \text { a } 0,1 \mathrm{~cm}^{3} \\
490 \text { dias }\end{array}$ & Positiva \\
\hline Lote 02 & $\begin{array}{c}0,13 \text { a } 0,3 \mathrm{~cm}^{3} \\
70 \text { dias }\end{array}$ & $\begin{array}{c}0,02 \text { a } 0,2 \mathrm{~cm}^{3} \\
72 \text { dias }\end{array}$ & Positiva \\
\hline
\end{tabular}

Os resultados de eficiência do ensaio de estanqueidade assim como a absorção de água apresentada pela tabela 07 , indicam menor absorção da água após o envelhecimento acelerado quando comparado com os substratos sem intemperismo.

Observou-se uma maior absorção de água para os substratos sem intemperismo quando comparado aos substratos com intemperismo em ambos os lotes. Verificou-se uma menor absorção de água do lote 01 quando comparado com o lote $02 \mathrm{em}$ ambos os tratamentos.

\section{CONSIDERAÇÕES FINAIS}

Este trabalho avaliou o desempenho da ATD (argamassa técnica decorativa) em relação à resistência de aderência à tração e estanqueidade pelo método do cachimbo antes e após a submissão de placas de substrato padrão ao envelhecimento acelerado proposto pela câmara de intemperismo. A partir dos resultados obtidos, pode-se concluir:

- A resistência de aderência à tração das placas com e sem intemperismo mostraram-se adequadas em relação à diretriz SINAT [9] e NBR 16648 [1].

- O ensaio de estanqueidade indicou menor absorção da água após o envelhecimento acelerado quando comparado com as placas sem intemperismo. A absorção de água dos substratos envelhecidos com 490 dias de idade foi menor que a absorção de água dos substratos com 72 dias de idade, indicando uma tendência de menor permeabilidade das ATDs ao longo do tempo.

- Nota-se que as placas que apresentaram maiores valores de resistência de aderência também apresentaram menor absorção de água após o intemperismo. Portanto, percebe-se correlação entre os resultados obtidos entre a resistência de aderência à tração e os resultados de estanqueidade para os substratos estudados.

Pode-se afirmar, de maneira geral, que em condições normais de estocagem, validade, dosagem, mistura e preparo as ATDs seguem um padrão regular de resistência à tração e absorção / permeabilidade uma vez que foram ensaiadas placas com 70 e 490 dias de idade.

\section{BIBLIOGRAFIA}

[1] ASSOCIAÇÃO BRASILEIRA DE NORMAS TÉCNICAS, ABNT NBR 16648: Argamassas inorgânicas decorativas para revestimento de edificações - Requisitos e métodos de ensaios, Rio de Janeiro: ABNT, 2018.

[2] HERRMANN, T. D., MOHAMAD, G., LIMA, R.C.A., et al., "Estudo de caso do desempenho de estanqueidade à água de argamassas e hidrorrepelentes - Parte I”. Revista Matéria, v. 24, n.04, 2019.

[3] ASSOCIAÇÃO BRASILEIRA DE NORMAS TÉCNICAS, ABNT NBR 15575: Edificações habitacionais - Desempenho, Rio de Janeiro: ABNT, 2013.

[4] OLSSON, L., "Rain resistance of façades with façade details: A summary of three field and laboratory studies", Journal of Building Physics, v. 41, pp. 521-532, 2018.

[5] PEREIRA, C., BRITO, J., SILVESTRE, J. D., "Contribution of humidity to the degradation of façade claddings in current buildings”, Engineering Failure Analysis, v. 90, pp. 103-115, 2018. 
[6] SALOMÃO, M.C.F., Estudo da estrutura das argamassas de revestimento e sua influência nas propriedades de transporte de água, Tese de D.Sc., Universidade de Brasília, DF, Brasil, 2016.

[7] ALIEVI, C.V., FOPPA, C., Projeto de Revestimento de Fachada, Revista Especialize On-line IPOG, 2016, Goiânia, v. 01, n.11, julho/2016,

[8] CRESCENCIO, R.M., BARROS, M.M.S.B, Tecnologia construtiva de revestimento decorativo monocamada, Informações Tecnológicas, Área Construção Civil, SENAI-SP editora, 104p. São Paulo/SP, 2013.

[9] SINAT, Diretriz No. 006 REV. 01: Revestimento decorativo monocamada em argamassa inorgânica, Diretriz para Avaliação Técnica de Produtos, Brasília, 2016.

[10] AZEVEDO, E.A.M, Revestimento Decorativo Monocamada Pigmentado, com Resíduo de Vidro Temperado, Para Aplicação em Fachadas, 146 p. Dissertação (Mestrado), Programa de Pós-Graduação em Engenharia Mecânica, Universidade Federal do Rio Grande do Norte, Natal, 2015.

[11] CSTC, Centre Scientifique et Technique de la Construccion - CSTC (2002), Hidrofuges de surface, Bruxelles, 51 p. (Note D'informationTechnique - NIT n. 224 - remplace la NIT n. 140).

[12] ASSOCIAÇÃO BRASILEIRA DE NORMAS TÉCNICAS, ABNT NBR 15258: Argamassa para revestimento de paredes e tetos - Determinação da resistência potencial de aderência à tração, Rio de Janeiro: ABNT, 2005.

[13] ASSOCIAÇÃO BRASILEIRA DE NORMAS TÉCNICAS, ABNT NBR 14081-2: Argamassa colante industrializada para assentamento de placas cerâmicas - Execução do substrato-padrão e aplicação de argamassa para ensaios, Rio de Janeiro: ABNT, 2015.

[14] CARASEK, H, Avaliação de resultados do ensaio de resistência de aderência de revestimentos de argamassa, Revista Techné, São Paulo, Ed. 185, junho/2012,

[15] RILEM - Rilem Test Method - Test No. II.4- Revised 2015 - Reunion Internationale des Laboratoires D'essais et de Recherches sur les Materiaux et les Constructions, 2015.

[16] DIAS, L.A., CARASEK, H, Avaliação da Permeabilidade e da Absorção de Água de Revestimentos de Argamassa pelo Método do Cachimbo, Anais do V Simpósio Brasileiro de Tecnologia da Argamassa (SBTA), São Paulo, 2003.

[17] BITENCOURT, S.C.S., Estudo da degradação acelerada da argamassa em um sistema de revestimento cerâmico de fachadas, Dissertação (Mestrado) - Universidade do Extremo Sul Catarinense, Programa de PósGraduação em Ciência e Engenharia de Materiais, Criciúma, SC, 2014, 129 p.

\section{ORCID}

Adriano de Paula e Silva

Antônio Neves de Carvalho Júnior

Gabriel Henriques Rabelo Gouvêa

Mauro Eugênio Lechi Vieira
https://orcid.org/0000-0003-4960-326X

https://orcid.org/0000-0001-7894-9345

https://orcid.org/0000-0003-3159-094X

https://orcid.org/0000-0002-6693-7774 